\title{
LEITURA E ESCRITA - AÇÕES LIBERTÁRIAS
}

\author{
READING AND WRITING - LIBERTARIAN ACTIONS
}

\author{
Rosemary Lapa de Oliveira ${ }^{1}$, Andréa Betânia da Silva ${ }^{1}$, Maria Alba Guedes Machado Mello ${ }^{1}$ \\ 1 Universidade do Estado da Bahia (UNEB), Salvador, BA, Brasil \\ rosy.lapa@gmail.com; andreabetania@gmail.com; maguedesmm@gmail.com
}

Recebido em 30 jun. 2018

Aceito em 8 ago. 2018

Resumo: Este artigo apresenta as ações de leitura para remição de pena para os privados de liberdade em regime fechado ou semiaberto. As ações de leitura e escrita denominada: "LEITURA E ESCRITA: Ações Libertárias" teve parceria com o Colégio Professor George Fragoso Modesto, situada no Complexo Prisional Lemos Brito, sediada em Salvador-BA e abarcou duas turmas de sentenciados. A ação foi apresentada na modalidade de curso de extensão, chancelado pela Universidade do Estado da Bahia - UNEB e priorizou o espírito de valorização dos diferentes momentos e tipos de aprendizagem associado à oferta de ações complementares de constituição de sujeitos leitores no contexto prisional, considerando experiências pioneiras no Brasil. A proposta de constituição de leitores intercríticos, autônomos e situacionados entende que a leitura conduz o sujeito a considerar várias possibilidades de atribuições de sentidos aos textos; que ler é processo de elaboração/criação constante de nossas vidas, de nossas práticas; e que, nesse processo, o contexto interfere na compreensão do sujeito, mas não é determinante. O curso de extensão "LEITURA E ESCRITA: Ações Libertárias" foi oferecido com carga horária de 60 horas, entre os dias 08 de agosto a 14 de dezembro de 2017, nas dependências do Complexo Prisional Lemos Brito, através da metodologia de rodas de leitura. Os resultados obtidos, além de remir a pena em duas semanas para os privados de liberdade, promoveu o enleituramento dos cursistas, ou seja, o diálogo do leitor com o texto de forma profunda, e o desejo da aprendizagem cada vez maior da decifração do código linguístico e da apropriação da leitura autônoma e crítica.

Palavras-Chave: Remissão de Pena. Leitura. Extensão

\begin{abstract}
This article presents the reading actions for remission of sentence for prisoners in a closed or semi-open regime. The actions of reading and writing denominated: READING AND WRITING Libertaian Actions had partnership with the Professor George Fragoso Modesto School, located in the Complex Lemos Brito, located in Salvador-Ba and comprised two classes of sentenced. The action was presented in the modality of extension course, by the University of Bahia State - UNEB and prioritized the spirit of valorization of the different moments and types of learning associated with the offer of complementary actions of constitution of subjects readers in the prison context, considering experiences pioneers in Brazil. The proposal for the constitution of intercritical, autonomous and situational readers understands that reading leads the subject to consider several possibilities of assigning meanings to texts; that reading is a process of constant elaboration / creation of our lives, of our practices; and that, in this process, the context interferes in the understanding of the subject, but it is not determinant. The READING AND WRITING extension course: Libertarian Actions was offered with a 60-hour workload, from August 8 to December 14, 2017, in the facilities of the Lemos Brito Prison Complex, through the methodology of reading wheels. The results obtained, in addition to remitting the sentence in two weeks for those deprived of liberty, promoted the enlightenment of the students and the desire to learn more and more about the deciphering of the linguistic code and the appropriation of autonomous and critical reading.
\end{abstract}

Keywords: Remission of sentence. Reading. Extension. 


\section{Introdução}

A Literatura é um autêntico exercício de vida, que se realiza com e na Linguagem, uma complexa forma pela qual o pensar se exterioriza e entra em comunicação com os outros pensares. Espaço de convergência do mundo exterior e do mundo interior (COELHO, 2000, p. 24) que concorre para a constituição de sujeitos leitores.

A escolha pela expressão/constituição de leitor e não "formação de leitor", neste texto, embora sejam expressões sinônimas, funda-se na significação dada pelo dicionário, a instituição do dizer, porém a licença social permite a diversidade de atribuições de sentidos. Sendo assim, indo à etimologia da palavra, temos em formare a ideia de dar forma a; já a palavra constituir tem a ideia de dar existência, juntar partes, o que se considera na presente proposta muito mais pertinente quando se fala de leitura na perspectiva aqui posta.

E por que sujeito leitor? Remetendo à gramática em que o sujeito é o responsável pela ação produzida, entende-se que quem lê não pode ser um objeto da leitura, no sentido de seguir ou obedecer ao que está escrito, o que seria uma impossibilidade mesma do ser humano, por conta de sua autonomia. Então, leitor é quem se faz sujeito de sua leitura, quem a ela dá sentidos e reavalia os seus próprios sentidos, no processo de leitura.

É nesta perspectiva e nestes termos que o curso de extensão "LEITURA E ESCRITA: Ações Libertárias" tem se apresentado ao variado público que se encontra no sistema prisional de Salvador, a Penitenciária Lemos de Brito, em parceria com o Colégio Professor George Fragoso Modesto, que funciona nesse complexo prisional.

Conforme determina a Recomendação do Conselho Nacional de Justiça (CNJ) n-44 de 26/11/2013, a qual dispõe sobre atividades educacionais complementares para fins de remição de pena pelo estudo e estabelece critérios para a admissão de Projetos, ancorada no disposto na Portaria Conjunta no 276, de 2/06/2012, nos Arts. 126 a 129 da Lei no 7.210/1984 (LEP) e na Lei no 12.433 de 29/06/2011 ${ }^{1}$, Súmula no 341 do STJ, dispõem sobre remição pela leitura para os privados de liberdade em regime fechado ou semiaberto.

\footnotetext{
${ }^{1}$ Altera a LEP, considerando os estudos para remição de pena.
} 
Assim, as ações de leitura no modelo rodas de leituras abarcou duas turmas de sentenciados, contando com trinta inscritos numa turma e vinte inscritos na outra, em dois módulos prisionais diferentes, referenciados aqui como módulos IV e I, ambos voltados para público masculino, uma vez que já existe uma ação de outra universidade com as privadas de liberdade desse sistema prisional.

A ação foi apresentada na modalidade de curso de extensão, chancelado pela Universidade do Estado da Bahia - UNEB e priorizou o espírito de valorização dos diferentes momentos e tipos de aprendizagens associados à oferta de ações complementares de constituição de sujeitos leitores no contexto prisional, considerando experiências pioneiras no Brasil. A proposta de constituição de leitores intercríticos, autônomos e situacionados entende que a leitura conduz o sujeito a considerar várias possibilidades de atribuições de sentidos aos textos; que ler é processo de elaboração/criação constante de nossas vidas, de nossas práticas; e que, nesse processo, o contexto interfere na compreensão do sujeito, mas não é determinante (no sentido do determinismo ideológico vigente no início do século $\mathrm{XX)}$.

A Recomendação CNJ nº 44 de 26/11/2013 orienta que sejam consideradas as atividades de caráter complementar, assim entendidas aquelas que ampliam as possibilidades de educação nas prisões, tais como as de natureza extensionistas, previstas nos diversos Projetos de Desenvolvimento Institucional - PDI das universidades públicas brasileiras. A extensão universitária, conforme consta no Regimento Geral da Universidade do Estado da Bahia ${ }^{2}$ (Arts.152 a 154 da seção IV do capítulo I), a qual chancela o curso de extensão em pauta, está colocada como interação da Universidade com a sociedade e difusão do conhecimento acadêmico, pontuando a presença da Universidade no contexto histórico da sociedade, propiciando o exercício permanente da cidadania. Além disso, a Extensão universitária é entendida como um processo educativo, cultural e científico, cujos cursos oferecidos ao público, sejam no âmbito universitário ou não, nas modalidades presencial ou a distância, têm o propósito de difundir os saberes históricos, artísticos

\footnotetext{
${ }^{2}$ Disponível em: http://www.uneb.br/files/2009/10/REGIMENTO-GERAL-DA-UNEB-2012.pdf. Acesso em 20 jun. 2016
} 
e culturais produzidos socialmente no sentido de contribuir com o desenvolvimento regional por meio da interação entre universidade e sociedade.

O curso de extensão "LEITURA E ESCRITA: Ações Libertárias" foi oferecido com carga horária de 60 horas, entre os dias 08 de agosto a 14 de dezembro de 2017, nas dependências do Complexo Prisional Lemos Brito, sendo que iniciamos as rodas de leitura com os privados de liberdade no módulo IV, no dia 17 de agosto, e no módulo I, no dia 24 de agosto. Os encontros aconteciam sempre às quintas-feiras à tarde, quando nos encontrávamos para dialogar sobre os textos lidos.

\section{Fundamentação teórico-metodológica}

Devido à complexidade dos estudos relativos à constituição de sujeitos leitores, urge assumir alguns posicionamentos teórico-metodológicos. Primeiramente, assumir, neste texto, a ideia de que ler vai além do domínio do código linguístico, concepção amparada em Freire (1996), o qual assevera que ler é um processo não restrito à decodificação linguística; extrapolando para a ideia nomeada por Soares (2004) como letramento. No mesmo campo conceitual, adotamos as contribuições de Rojo (2012) com as discussões sobre multiletramentos e foi além, interagindo com a ideia de enleituramento, termo cunhado em estudo de doutoramento para dar conta da capacidade humana de tornar-se leitor de mundo, tendo na leitura uma ação que é contínua e ampliada a cada contato com o contexto que cerca o leitor e a produção lida. O leitor faz seu contato com o texto, imergindo no contexto dos acontecimentos que compõem a teia textual (OLIVEIRA, 2015).

A leitura, conforme aqui tratada, e a escrita são ações performáticas que ensejam um processo terapêutico de envolvimento do sujeito psicossocial com o meio no qual se encontra. A leitura não só informa, mas ensina e transforma. $A$ escrita não só revela o que pensamos, mas mesmo o que somos e como poderemos ser. São ações envolvidas na constituição do sujeito social e civil dada a condição reflexiva que promove nos sujeitos da leitura e da escrita. Trata-se de uma ética configurada esteticamente, conforme nos ensina Jorge Larrosa (1994, p. 77) que assevera: 
No campo moral, a construção e a mediação da experiência de si têm a ver, então, com a dimensão de juízo que pode ser estritamente jurídica (baseada na lei), normativa (baseada na norma), ou estética (baseada em critérios de estilo). Mas, em todos os casos, teríamos a constituição simultânea de um sujeito que julga um conjunto de critérios (um código de leis, um conjunto de normas ou uma série de critérios de estilo), e um campo de aplicação. (LARROSA, 1994, p. 77)

Sendo assim, temos ações que podem fomentar práticas pedagógicas nas quais o importante é que se elabore e reelabore alguma forma de relação reflexiva de quem lê consigo mesmo, o que Foucault (apud LARROSA, 1994) chama de ontologia histórica de nós mesmos, que direciona para mecanismos que transformam os seres humanos em sujeitos. Uma construção e mediação pedagógica da experiência de si e, assim, conceder voz aos excluídos sociais, para que possam ser revistos preconceitos ligados aos transgressores, apontados como pessoas de um único tempo - o do delito - , e condenados como irrecuperáveis, conforme Câmara (2011) defende. Tudo isso mediado pela literatura que, com base nos estudos de Coelho (2000), é vista como arte, fenômeno de criatividade que representa o mundo, o homem, a vida, através da palavra, que funde os sonhos e a vida prática, o imaginário e o real, os ideais e sua possível/impossível realização. Por se tratar de uma linguagem específica como outras linguagens, expressa uma experiência humana que não pode ser definida com exatidão. A Literatura é complexa, fascinante, misteriosa e essencial, tanto quanto a condição humana dos sujeitos.

Coracini (2005), ao traçar diferentes concepções de leitura, entre a modernidade e a pós-modernidade, primeiro define ler, situando-o como o olhar, o qual, diz ela, "pode ser direto, atravessado ou enviesado, conforme o leitor, o espectador, o observador, sua bagagem de vida, o contexto social no qual se insere: momento e espaço (lugar), suas expectativas" (CORACINI, 2005, p. 19), uma definição que se afina com a epistemologia adotada neste projeto. E ressalta o teor inconsciente de tais fatores. Assim, abordando 0 ato de ler, ela apresenta duas concepções clássicas de leitura na modernidade: "1) leitura enquanto decodificação: descoberta do sentido; 2) leitura enquanto interação: construção do sentido" (CORACINI, 2005, p. 20). Situando historicamente - mas não cronologicamente -, temos uma concepção de leitura que visa à busca de uma verdade, uma essência capturável no texto (sempre visto de forma ampla), sendo o sujeito-leitor, nesse 
caso, apenas leitor - decodificador do código escrito - que deve resgatar essa verdade imparcialmente.

No sentido da interação, a diferença é que a verdade se desloca do escrito para quem escreveu, mas a ideia continua sendo a mesma. Continuando suas reflexões, essa autora apresenta a concepção de leitura na perspectiva da pósmodernidade como "leitura enquanto processo discursivo" (CORACINI, 2005, p. 23); nessa perspectiva, já se encontra o sujeito-leitor dialogando com o sujeito autor, construindo sentidos vários e eventualmente refutáveis, inclusive.

Sem discordar de Coracini (2005), Nunes (2003) situa historicamente a constituição leitora nos espaços de circulação do poder, considerando que o sujeito constitui-se como leitor dentro de uma memória social de leitura: na Idade Média, dominantemente localizada no espaço religioso; na época moderna, no espaço literário e no científico; hoje, circulando entre o jurídico, o econômico e o político. Muitos ainda convergem com a concepção trazida por Coracini (2005), situando a leitura na modernidade, muito embora, os textos que circulam no meio jurídico, econômico e político exijam uma leitura mais autônoma como nos ensina Freire (2009), ou seja, atribuição de sentido ao texto construído a partir das informações contidas no próprio texto e dos conhecimentos prévios do leitor, possibilitando o desenvolvimento do raciocínio.

Segundo Bettelheim (2002) é a literatura quem melhor canaliza a oportunidade de entendimento de si e das coisas do mundo, assim, diz ele, é preciso promover a capacidade de encontrar sentido na vida, dotar a vida, em geral, de mais significados. Com respeito a essa tarefa, ressalta esse autor, assume grande importância a família e a escola, além da nossa herança cultural, transmitida socialmente.

De acordo com Souza (2010, p. 9), "a literatura é antes de tudo engenharia de palavras. É por meio da palavra oral ou escrita que ela se realiza”. A literatura é arte, é cultura, é uma viagem pelo mundo da fantasia, em mundos conhecidos e desconhecidos, nos quais a criança (e também o adulto) depara-se com o novo e experimenta as mais diversas sensações de prazer, emoção e imaginação... é um grande encontro com o belo. Esses são elementos fundamentais para que o sujeito 
seja capaz de compreender a si e o meio ao qual pertence, construindo conhecimentos sólidos para que possa entender o mundo de forma prazerosa.

A literatura, segundo Lajolo (2000), é uma ferramenta que auxilia no processo de ensino e de aprendizagem, pois apresenta um caráter pedagógico, no sentido apresentado por Bettelheim (2002), como vimos acima. Sendo um componente interdisciplinar, transversal e cultural, por exercer a função de agente de transformação, - uma vez que contribui para a formação intelectual e sociocultural -, contribui para uma formação integral, provocando inúmeras emoções e sensações, dando prazer e divertindo, fazendo com que o sujeito transforme-se em leitor capaz de ver o mundo em mais de uma perspectiva.

A literatura - vista aqui de modo bastante amplo, focando a interação —, aponta caminhos possíveis para a constituição de leitor que assegure o exercício da autonomia pregada por Freire (1996), ou seja, autonomia reforçada com base nas decisões, das vivências, da própria liberdade, à medida que esteja vinculada à ideia de dignidade. E, para Freire (1996), a educação deve proporcionar contextos formativos que sejam adequados para que os educandos possam fazer-se autônomos. Essa temática ganha em Freire (no conjunto de sua obra) um sentido sócio-político-pedagógico: autonomia é a condição socio-histórica de um povo ou pessoa que tenha se libertado, se emancipado, das opressões que restringem ou anulam sua liberdade de determinação. E conquistar a própria autonomia implica, para este pensador, libertação das estruturas opressoras. Nesse curso, isso redunda em ações de apresentação de diálogos com textos nem sempre tão canônicos, além do exercício da produção textual de narrativas.

\section{Articulação Institucional}

A inserção da Universidade do Estado da Bahia (UNEB) na Educação para os privados de liberdade foi motivada por docentes e gestores do Colégio Professor George Fragoso Modesto, pertencente à rede estadual de ensino, no sentido de articular a Educação Básica às Instituições de Educação Superior, particularmente à UNEB, na qual alguns dos professores já haviam cursado mestrados e graduações. Com o incentivo da Recomendação CNJ no 44 de 26/11/2013 que estende o direito à 
remição da pena pelo estudo a ações de formação de leitores, o Colégio Professor George Fragoso Modesto nos sugeriu a elaboração e execução de um projeto de leitura. Essa Recomendação foi normatizada pelo Conselho Penitenciário do Estado da Bahia - COPEN, vinculado à Secretaria de Administração Penitenciária - SEAP, a quem cabe regulamentar, para o Sistema Penitenciário da Bahia, as ações e determinações legais no sentido do cumprimento das normativas do Conselho Nacional de Justiça.

A UNEB, por meio do seu Departamento de Educação no Campus I, e o Colégio Professor George Fragoso Modesto trabalharam no sentido do reconhecimento da extensão universitária como uma das modalidades da oferta da formação de leitores, junto ao Conselho Estadual de Educação - CEE e ao COPEN, o que ficou estabelecido na proposta de Resolução do COPEN encaminhada à Corregedoria dos Presídios do Tribunal de Justiça da Bahia, em setembro 2017. Nesse processo, pudemos apresentar e discutir o Projeto "LEITURA E EsCRITA: Ações Libertárias" ao CEE, ao COPEN, à juíza dos sentenciados internos da Penitenciária Lemos Brito, assim como ao juiz corregedor do Tribunal de Justiça do Estado da Bahia, cujas contribuições e orientações sobre procedimentos para a remição de pena foram importantes para o desenvolvimento do nosso projeto de extensão. Encaminhamos ainda ao corregedor geral de presídios do Ministério Público da Bahia, do qual ainda não tivemos uma devolução.

O Conselho Estadual de Educação - CEE possui uma Resolução ${ }^{3}$ na qual se compromete com a fiscalização e avaliação do Plano Estadual de Educação em estabelecimentos Prisionais no Estado da Bahia em cujas metas constam a articulação entre a rede pública de Educação Básica e as Instituições de Ensino Superior sob sua jurisdição (no caso as UEBAs) e a oferta do nível superior aos privados de liberdade; tem, portanto, o CEE, interesse de acompanhamento desta aproximação da UNEB com o sistema prisional baiano. O Conselho Penitenciário do Estado da Bahia é, como já foi dito, a instância responsável pela normatização das ações no interior do sistema prisional baiano e foi bastante receptivo na audição da nossa proposta (elaborada e exposta juntamente com os professores do Colégio

\footnotetext{
${ }^{3}$ no 43/2014 que dispõe sobre a oferta, pelo Sistema Estadual de Ensino, da Educação Básica na modalidade Educação de Jovens e Adultos, para pessoas em situação de privação de liberdade nos estabelecimentos penais do Estado da Bahia (Parecer CEE № 113/2014).
} 
Professor George Fragoso Modesto), particularmente pelo seu ineditismo ${ }^{4}$; este mesmo conselho requereu as audiências com as autoridades do judiciário (juíza e corregedor) para apresentação e legitimação do projeto.

O ambiente prisional exige uma articulação interinstitucional, pois a própria natureza do sistema prisional demanda ações do âmbito da justiça, da administração prisional e dos órgãos responsáveis pelas ações setoriais de educação, saúde e assistência social que são os garantidores e executores dos direitos dos cidadãos, inclusive dos que estão em situação de privação de liberdade. Entretanto, a nossa cultura política é fortemente marcada pela duplicação de esforços e conflito de interesses entre órgãos públicos no interior da própria gestão do Estado, seja porque os critérios de composição das equipes de governo não propiciam a integração entre secretarias, seja pela própria complexidade das relações entre Estado e sociedade civil. O fato é que uma ação institucional, como esta da UNEB, não pode (e nem deve) efetivar-se sem as devidas permissões e parcerias. Essa 'condição de trabalho' nos exige e nos impõe o diálogo e a negociação político-institucional no sentido de legitimação das nossas ações, no caso, a remição de pena pela leitura certificada como extensão universitária. Por isso, dividimos as atribuições cotidianas (formação de turmas, seleção dos monitores internos e de professores colaboradores) com o referido Colégio e incluímos a produção dos nossos cursistas no projeto didático-pedagógico denominado Sarau Literário.

\section{Desenvolvimento do Curso}

As ações do curso não se limitaram aos encontros presenciais de roda de leitura, foi sempre necessário que os participantes do curso dedicassem um mínimo de uma hora de leitura e escrita diárias para que as ações ocorridas nos encontros das rodas de leitura se efetivassem. E, de fato, essas ações eram ocorriam de forma propícia e plena, revelando que as horas de leituras e escritas diárias foram realizadas.

Os encontros contavam com uma média de 20 privados de liberdade e uma equipe composta sempre de duas professoras doutoras da UNEB, um ou dois

\footnotetext{
${ }^{4} \mathrm{O}$ único projeto de leitura, dentre os existentes em outros Estados brasileiros e na Bahia, que se caracteriza como extensão universitária.
} 
professores do Colégio Professor George Fragoso Modesto, de monitoras de extensão da UNEB e monitores internos, privados de liberdade, indicados pela equipe da penitenciária para assessorar os participantes durante a semana, ajudando-os na escolha dos livros a serem lidos, ajudando-os na leitura e na escrita, caso ainda não a tenham dominado de forma autônoma.

O objetivo original do curso de extensão foi disponibilizar educação a adultos e idosos que cumprem pena em regime aberto ou semiaberto, por meio do conhecimento gerado e/ou sistematizado pelas instituições universitárias, com intenções de concorrer para o seu desenvolvimento humano no âmbito individual e coletivo. Essa disponibilização de educação foi oferecida por meio da literatura, considerando seu viés ao mesmo tempo lúdico e reflexivo, o que foi bastante explorado durante os encontros. Assim, foram oferecidas possibilidades de contato com variados textos da literatura nacional e internacional, conforme o acervo encontrado nas dependências do sistema prisional e de material selecionado e levado pelas responsáveis pelo curso junto à UNEB, as professoras que assinam esse relatório. Toda a seleção de textos visou alcançar o desenvolvimento de compreensão leitora com vistas a constituir leitores. Trabalhamos poemas, minicontos, cordéis, placas, revistinhas em quadrinhos, anúncios, contos, travalínguas e, apenas no módulo 4, com romances.

A lógica do curso girou sempre em torno do binômio leitura/escrita. A cada leitura de gêneros textuais variados, iam sendo gerados textos autorais também variados, produzidos por seus leitores. As produções foram invariavelmente individuais e autorais, sempre inspiradas nas leituras produzidas, considerando, claro, os saberes e contextos de histórias de vida de cada um. Os textos lidos eram apresentados na forma de resumo oral e, após essa apresentação, era realizada a leitura dos textos produzidos e compilados em anexo.

\section{Metodologia}

O curso foi desenvolvido através de ações de monitorias, priorizando o diálogo constante entre os sujeitos interactantes do curso, em que as ações de fazer foram desenvolvidas e dialogadas no espaço pedagógico a nós destinado - celas 
transformadas em igrejas evangélicas - articulando-se aos trabalhos curriculares do Colégio Professor George Fragoso Modesto, instalada no complexo Penitenciário Lemos Brito.

No primeiro encontro, foi apresentada a proposta do curso aos privados de liberdade selecionados para o curso e feita uma pesquisa sobre a literatura que interessava a esses sujeitos. Iniciamos as rodas de leitura com a história dos nomes dos cursistas: quem escolheu, os motivos das escolhas, o significado dos mesmos etc. Todos os nomes têm uma história e nomes iguais tem histórias diferentes... um prazeroso exercício de conhecimento de si e do outro.

Nas reuniões de debate sobre os textos lidos foram sempre estimulados posicionamentos críticos de todos os presentes, no sentido de acionar seus conhecimentos de mundo para dialogar com os textos selecionados para aquele momento. Esse momento, também, era aberto para que as pessoas participantes do encontro ficassem à vontade para ler ou contar ou declamar, sendo, para isso, estimulados pela dinâmica de deguste de textos variados trazidos para o encontro.

Assim, em reuniões prévias aos encontros, selecionávamos textos narrativos, poéticos e multimodais para o trabalho em cada um dos doze encontros de roda de leitura que se desenvolveram semanalmente. Nos encontros semanais, estavam presentes: professoras doutoras da UNEB; professores do Colégio Estadual George Fragoso Modesto, que se disponibilizaram a participar das rodas por vontade própria; estudantes da UNEB, como monitoras do projeto; privados de liberdade, que fizeram monitoria interna das rodas de leitura e, eventualmente, também participavam os agentes penitenciários.

As ações desenvolvidas se apresentavam como sequências didáticas que ocorreram invariavelmente da seguinte forma:

1. O primeiro momento: ouvir as produções referentes às leituras realizadas durante a semana, dialogando com os textos escritos produzidos, tentando sempre levantar um pensamento crítico e desconstruir julgamentos, mantendo a ideia de que há várias interpretações possíveis para cada texto, além de priorizar a abertura da palavra para quem quiser dialogar com o texto apresentado pelos colegas. O debate foi uma constante (raros encontros não houve debate) e mostraram-se bastante profícuos . 
2. No segundo momento: começar a rodada de apresentação dos textos a serem produzidos para o próximo encontro. Assim, caso quiséssemos que os cursistas produzissem anúncios publicitários sobre o livro lido, então apresentávamos anúncios/propagandas variadas para eles; caso desejássemos que produzissem cordéis, apresentávamos cordéis a eles e dialogávamos sobre suas características e assim por diante.

3. No terceiro momento: Apresentávamos a proposta de tarefa da semana, sempre um desafio a ser alcançado por eles: resumo crítico, paródia, conto, poesia, miniconto, cordel, anúncio/propaganda, refacção de final, memorial, foram alguns dos gêneros textuais produzidos, inspirados nas leituras realizadas.

Ao final de cada encontro, os textos produzidos foram recolhidos, digitados e digitalizados para efeito de registro, com vistas a possível futura publicação.

A Penitenciária Lemos de Brito divide os internos em módulos, conforme especificações da própria instituição e não há diálogo entre internos de módulos diferentes. Assim, o curso ocorria em dias diferentes nos módulos I e VI, com privados de liberdade de cada um desses módulos que foram selecionados pelos agentes penitenciários, considerando critérios que não nos foram revelados.

Os participantes do curso de extensão do módulo IV tiveram acesso aos textos a serem lidos disponibilizados pelas próprias professoras e/ou através dos monitores internos que também orientavam a leitura do acervo pré-existente no Colégio Professor George Fragoso Modesto. No módulo I, no qual não há acervo organizado e acessível aos privados de liberdade, os textos foram aqueles disponibilizados pelas professoras durante as rodas de leitura. Nos dois módulos, além de orientar a leitura, para aqueles que estavam em processo de alfabetização, os monitores internos liam em voz alta e eram escribas desses colegas. Essa ação possibilitou que mesmo quem não dominasse a leitura fosse capaz de participar ativamente do curso.

Os textos produzidos, em linguagem verbal escrita, oral, imagética ou mista, foram mediados pelas professoras da UNEB e monitores estudantes, e tiveram tratamento de refacção mediado, até que estivessem compatíveis com o gênero textual adotado. Ao final do curso de extensão, cada interno teve contato com 
diversos gêneros literários: poesias, romance, conto, autobiografia, biografia, trava línguas, cordel, histórias em quadrinhos, anúncios poéticos. E produziram a mesma variedade de textos baseados nas leituras realizadas. Essas produções foram organizadas para fazerem parte de uma coletânea de escritos dos apenados, conforme previa o projeto do curso.

A proposta de produção de texto considerou as discussões que se desenvolveram durantes os encontros de debate e tinha, eventualmente, teor autobiográfico, estimulando o diálogo do sujeito leitor com o texto lido, assumindo o papel de produtor de conhecimento, de autoria, experienciando o sabor de produzir leituras para outrem. Essas produções eram apresentadas na forma verbal escrita, verbal oral, com auxílio de escriba (nesse caso, papel dos monitores), imagética ou de outras linguagens. Esses textos serviram de avaliação do processo de leitura.

\section{Considerações finais}

Podemos dizer que o curso se configurou como uma construção e mediação pedagógica da experiência de si, concedendo voz aos excluídos sociais, para que possam ser revistos preconceitos ligados aos transgressores, apontados como pessoas de um único tempo - o do delito - e condenados como irrecuperáveis, conforme Câmara (2011) defende. As ações ali desenvolvidas puderam fomentar práticas pedagógicas nas quais o importante foi a elaboração e reelaboração da relação reflexiva de quem lê consigo mesmo, o que Foucault (apud LARROSA, 1994) chama de ontologia histórica de nós mesmos, a qual direciona para mecanismos que transformam os seres humanos em sujeitos.

Tudo isso mediado pela literatura que, com base nos estudos de Coelho (2000), é vista como arte, fenômeno de criatividade que representa o mundo, o homem, a vida, através da palavra, que funde os sonhos e a vida prática, o imaginário e o real, os ideais e sua possível/impossível realização. Por se tratar de uma linguagem específica como outras linguagens, expressa uma experiência humana que não pode ser definida com exatidão. A Literatura é complexa, fascinante, misteriosa e essencial, tanto quanto a condição humana dos sujeitos. 
A leitura constitui-se, enfim, um instrumento para a compreensão do mundo. Esse posicionamento corrobora com a ideia defendida por Gregorin Filho (2009) de que aprender a ler e utilizar-se da leitura como veículo de informação e lazer contribui para a formação de um sujeito com poder de argumentação, capaz de interagir com o mundo que o rodeia e tornar-se agente modificador, transformador da sociedade à qual pertence. Esse é o posicionamento perseguido neste curso de extensão em cada uma das atividades de leitura e escrita de texto poético, narrativo, imagético ou multimodal.

\section{Referências bibliográficas}

BETTELHEIM, B. A psicanálise dos contos de fadas. 16. ed. São Paulo: Paz e Terra, 2002.

CÂMARA, H. F. Reinvenções da vida em escritas na prisão. In: Em Aberto / Instituto Nacional de Estudos e Pesquisas Educacionais Anísio Teixeira. v.1, n. 1, (nov. 1981). Brasília: INEP, 2011.

COELHO, N. N. Literatura: arte, conhecimento e vida. São Paulo: Editora Fundação Peirópolis, 2000. (Série nova consciência)

CORACINI, M. J. R. F. Concepções de leitura na (pós) modernidade. In: LIMA, R. C. C. P. (org). Leituras: múltiplos olhares. Campinas, SP: Mercado de Letras, 2005.

FREIRE, P. A importância do ato de ler em três artigos que se completam. 22. ed. São Paulo: Autores Associados: Cortez, 2009.

. Pedagogia da autonomia: saberes necessário à prática docente. São Paulo: Paz e Terra, 1996.

GREGORIN FILHO. J. N. Literatura infantil: múltiplas linguagens na formação de leitores. São Paulo: Melhoramentos, 2009.

LAJOLO, M. Do mundo da leitura para a leitura do mundo. 5. ed. São Paulo: Ática, 2000.

LARROSA, J. Tecnologias do eu e educação. In: SILVA, Tomaz T. da (Org.). sujeito da educação: estudos foucaultianos. Petrópolis, RJ: Vozes, 1994.

NUNES, L. R. Linguagem e Comunicação Alternativa: Uma introdução. In: NUNES, L. R. (Org). Favorecendo o desenvolvimento da comunicação em crianças e jovens com necessidade educacionais especiais. Rio de Janeiro: Dunya, 2003. 
OLIVEIRA, R. L. A Pedagogia da Rebeldia e Enleituramento: a constituição do sujeito leitor. Saarbrücken-Alemanha: Novas Edições Acadêmicas, 2015.

ROJO, R. H. R. Pedagogia dos multiletramentos: diversidade cultural e de linguagens na escola. In: ROJO, R. H. R.; MOURA, E. Multiletramentos na escola. São Paulo: Parábola Editorial, 2012.

SOARES, M. Letramento e alfabetização: as muitas facetas. Rev. Bras. Educ. [online]. 2004, n.25, pp. 5-17. ISSN 1413-2478. http://dx.doi.org/10.1590/S141324782004000100002.

SOUZA, A. A. Literatura infantil na escola: a leitura em sala de aula. Campinas, SP: Autores Associados, 2010.

\footnotetext{
Sobre as autoras

Rosemary Lapa de Oliveira

Professora Adjunta DE do curso de Pedagogia da Universidade do Estado da Bahia e do Programa de Pós-Graduação em Educação e Contemporaneidade, coordenando a pesquisa LEITURA NA ESCOLA. Pós-doutoranda em Educação, Doutora em Educação e Mestre em Letras e Linguística pela Universidade Federal da Bahia. Especialista em Gramática e Texto pela Universidade Salvador. Licenciada em Letras Vernáculas com Inglês e Literaturas pela Universidade Católica do Salvador. Atuou no Mestrado Profissional em Letras - PROFLETRAS (2016-2018) e no Mestrado Profissional em Educação de Jovens e Adultos - MPEJA (2016-2018). Vice-líder do grupo de pesquisa Formacce Infância, Linguagens e EJA - DEDC I - UNEB.

\section{Andréa Betânia da Silva}

Professora adjunta da Universidade do Estado da Bahia - Departamento de Educação - Campus I. Doutora em Cultura e Sociedade pela Universidade Federal da Bahia em co-tutela com a Université Paris Ouest Nanterre La Défense. Mestre em Letras pela Universidade Federal da Bahia, Especialista em Língua Portuguesa pela Universidade Estadual de Santana e Graduada em Letras Vernáculas pela mesma instituição.

\section{Maria Alba Guedes Machado Mello}

Professora adjunta da Universidade do Estado da Bahia - Uneb - Campus I. Doutora em Educação e Contemporaneidade pela Universidade do Estado da Bahia (2015), Mestre em Ciências Sociais pela Universidade Federal da Bahia (1990) e licenciada em História pela Universidade Federal da Bahia (1983).
} 